\title{
Results and complications of surgeons-in-training learning bimanual microincision cataract surgery
}

\author{
Gian Maria Cavallini, MD, Veronica Volante, MD, Tommaso Verdina, MD, Matteo Forlini, MD, \\ Maria Chiara Bigliardi, MD, Michele De Maria, MD, Giulio Torlai, MD, Giancarlo Delvecchio, MD
}

PURPOSE: To evaluate visual outcomes and complications of bimanual microincision cataract surgery performed by surgeons in training.

SETTING: Institute of Ophthalmology, University of Modena and Reggio Emilia, Modena, Italy.

DESIGN: Prospective case series.

METHODS: The corrected distance visual acuity (CDVA), astigmatism, corneal pachymetry, and endothelial cell count were evaluated before and 7 and 30 days after bimanual MICS performed by surgeons in training. Intraoperative and postoperative complications were also recorded.

RESULTS: Three surgeons in training performed bimanual MICS in 150 eyes of 131 patients. There were 18 intraoperative complications (12.0\%) (10 iris traumas [6.6\%]; 4 capsule ruptures without vitreous loss [2.7\%]; 3 capsule ruptures with vitreous loss [2.0\%]; 1 intraocular lens [IOL] implantation in the sulcus due to zonular laxity [0.7\%]). There were 5 postoperative complications $(3.3 \%)$ (2 iris prolapses [1.3\%]; 1 IOL loop malposition [0.7\%]; 1 narrowing of anterior chamber [0.7\%]; 1 capsulorhexis phimosis [0.7\%]). Thirty days postoperatively, the mean CDVA improvement was $0.53 \pm 0.20$ (Snellen decimal) $(P<.05)$, the mean decrease in astigmatism was $0.09 \pm 0.54$ diopter $(P=.29)$, and the mean increase in corneal pachymetry was $7.42 \pm 22.01 \mu \mathrm{m}(P=.12)$. There was statistically significant endothelial cell loss (mean $\left.496.50 \pm 469.66 \mathrm{cells} / \mathrm{mm}^{2}\right)(P<.05)$.

CONCLUSIONS: Bimanual MICS performed by surgeons in training was safe and effective. Visual outcomes and complication rates were similar to those reported for coaxial cataract surgery performed by surgeons in training.

Financial Disclosure: No author has a financial or proprietary interest in any material or method mentioned.

J Cataract Refract Surg 2015; 41:105-115 @ 2015 ASCRS and ESCRS

Cataract surgery has continually evolved, and progress in technology and equipment has permitted a reduction in incision size. This has led to the development of microincision cataract surgery (MICS) techniques. ${ }^{1}$ Two MICS techniques are available; that is, coaxial and bimanual (or biaxial).

In bimanual MICS, ${ }^{2}$ the aspiration probe and the infusion probe are separated. This enables surgery to be performed through incisions that are $1.5 \mathrm{~mm}$ or smaller. In coaxial MICS, ${ }^{3}$ in which infusion and aspiration are in the same probe, incisions range from 1.8 to $2.2 \mathrm{~mm}$. The bimanual MICS technique is less invasive than traditional coaxial phacoemulsification, and it uses the smallest incisions of any cataract surgery technique. This is important because clinical studies have shown that the size of the incision is directly proportional to the amount of surgically induced astigmatism (SIA) and inversely proportional to the stability of astigmatism over time. ${ }^{4}$ The main advantages of this technique are increased stability of the anterior chamber, the ability to direct instruments in different directions as required by the surgeon (eg, to keep the posterior capsule far from the phaco tip), the ability to use the right hand or left hand, and greater visibility of the surgical field because of the small instruments. These features are especially helpful to less experienced 
surgeons, such as those in training or using the bimanual technique for the first time.

To our knowledge, there are no studies of the incidence of complications during the training stage of bimanual MICS. The goal of our study was to evaluate the first cases of bimanual MICS of surgeons in training. The main intraoperative and postoperative complications during the learning curve were evaluated. Other postoperative outcome measures were visual acuity, astigmatism, corneal thickness, and the endothelial cell count (ECC).

\section{PATIENTS AND METHODS}

This prospective study evaluated the outcomes of bimanual MICS performed by surgeons in training at the Institute of Ophthalmology, University of Modena and Reggio Emilia, Modena, Italy. All patients provided informed consent before surgery.

All surgeries recorded were the first bimanual MICS performed by each surgeon as well as all subsequent surgeries performed using the technique over 6 months. The surgeons were under the direct supervision of experienced surgeons, who offered guidance or intervened when necessary. All surgeons in training had little experience in the coaxial technique.

The inclusion criteria was cataract from grade 2 to 3 on the Lens Opacities Classification System III. ${ }^{5}$ Exclusion criteria were previous surgery, complicated cataract (eg, total cataract, traumatic cataract), concomitant pathology (uveitis, glaucoma, corneal opacities), insufficient mydriasis $(<4.0 \mathrm{~mm})$, and a low ECC $\left(<1500\right.$ cells $\left./ \mathrm{mm}^{2}\right)$. Patients with 1 eye only were also excluded.

\section{Preoperative Assessment}

Before surgery, the patient's medical history was recorded. Examinations included corrected distance visual acuity (CDVA), anterior segment biomicroscopy, fundus evaluation, biometry (IOLMaster, Carl Zeiss Meditec AG, and US500 Echoscan, Nidek Technologies Srl), corneal microscopy (Noncon Robo, Konan Medical), corneal pachymetry (IOPac, Heidelberg Engineering $\mathrm{GmbH}$ ), and corneal topography (CT1000, Shin-Nippon).

\section{Prophylaxis}

Prophylactic strategies to prevent infections included application of topical antibiotic eyedrops before surgery, application of povidone-iodine $5.0 \%$ to the conjunctival

Submitted: February 5, 2014.

Final revision submitted: April 6, 2014.

Accepted: April 11, 2014.

From the Institute of Ophthalmology, University of Modena and Reggio Emilia, Modena, Italy.

Corresponding author: Gian Maria Cavallini, MD, Struttura Complessa di Oftalmologia, Azienda Ospedaliero-Universitaria di Modena Policlinico, Via del Pozzo 71, 41100, Modena, Italy. E-mail: cavallini.gianmaria@unimore.it.

\begin{tabular}{|lccc|}
\hline \multicolumn{4}{l}{ Table 1. Phaco machine parameters. } \\
\hline Parameter & Phase 1 & Phase 2 & Epinucleus Phase \\
\hline US power (\%) & 25 & 35 & 10 \\
Vacuum (mm Hg) & 110 & 260 & 180 \\
Bottle height (cm) & 110 & 110 & 110 \\
\hline US = ultrasound & & & \\
\hline
\end{tabular}

cul-de-sac, preparation of the periocular skin with povidone-iodine $10.0 \%$, careful sterile draping of the eyelid margins and eyelashes, addition of antibiotics to the irrigating solution, instillation of intracameral antibiotics at the end of surgery, and application of topical antibiotic eyedrops after surgery.

\section{Surgical Technique}

Each surgeon in training performed 50 operations using the same phaco machine (Stellaris, Bausch \& Lomb). Table 1 shows the phaco machine settings used.

Mydriasis was obtained by instilling atropine $1.0 \%$, phenylephrine $10.0 \%$, and cyclopentolate $1.0 \%$. Regional anesthesia was achieved using a retrobulbar block $(2.5 \mathrm{~mL}$ lidocaine $2.0 \%$ and $2.5 \mathrm{~mL}$ bupivacaine $0.5 \%$ ). In all cases, a balanced salt solution for irrigation and sodium hyaluronate $1.2 \%$ (Amvisc) were used. Two $1.4 \mathrm{~mm}$ trapezoidal incisions were created in clear cornea at 10 o'clock and 2 o'clock with a precalibrated diamond knife (ME 772 DA, E. Janach S.r.1.). After a continuous curvilinear capsulorhexis (CCC) was made with a cystotome and microforceps (E. Janach S.r.l.), hydrodissection was performed with a 26-gauge cannula. Then, phacoemulsification was performed with a 20-gauge, 30-degree angled sleeveless probe and an irrigating chopper (Bragamele 19-gauge). Phacofracture was obtained with the stop-and-chop technique. Irrigation/aspiration (I/A) was performed with a 21-gauge probe with an oval-shaped section (21-gauge irrigation handpiece smooth, Stellaris; 21-gauge aspiration handpiece rough, Bausch \& Lomb). All surgeons used continued infusion during phacoemulsification and I/A. In the final stages of surgery, the 10 o'clock incision was enlarged to $1.8 \mathrm{~mm}$ with a precalibrated knife (Alio MICS multi-incision knife, Katena Inc.) and the intraocular lens (IOL) was implanted. The incisions were closed using hydration or sutured with 10-0 nylon. Figure 1 shows the main steps of the technique.

Postoperative therapy consisted of tobramycin and dexamethasone eyedrops 4 times a day for 15 days followed by flurbiprofen eyedrops 3 times a day for a further 15 days.

\section{Intraoperative Assessment}

The following intraoperative parameters were recorded: total surgery time (from first corneal incision to incision hydration or suture), mean phacoemulsification time, effective phacoemulsification time (EPT), final incision size (measured with a surgical caliper), and balanced salt solution use (calculated by subtracting residual volume at end of surgery from initial volume in infusion bottle). Intraoperative complications were registered at the end of every surgery. 


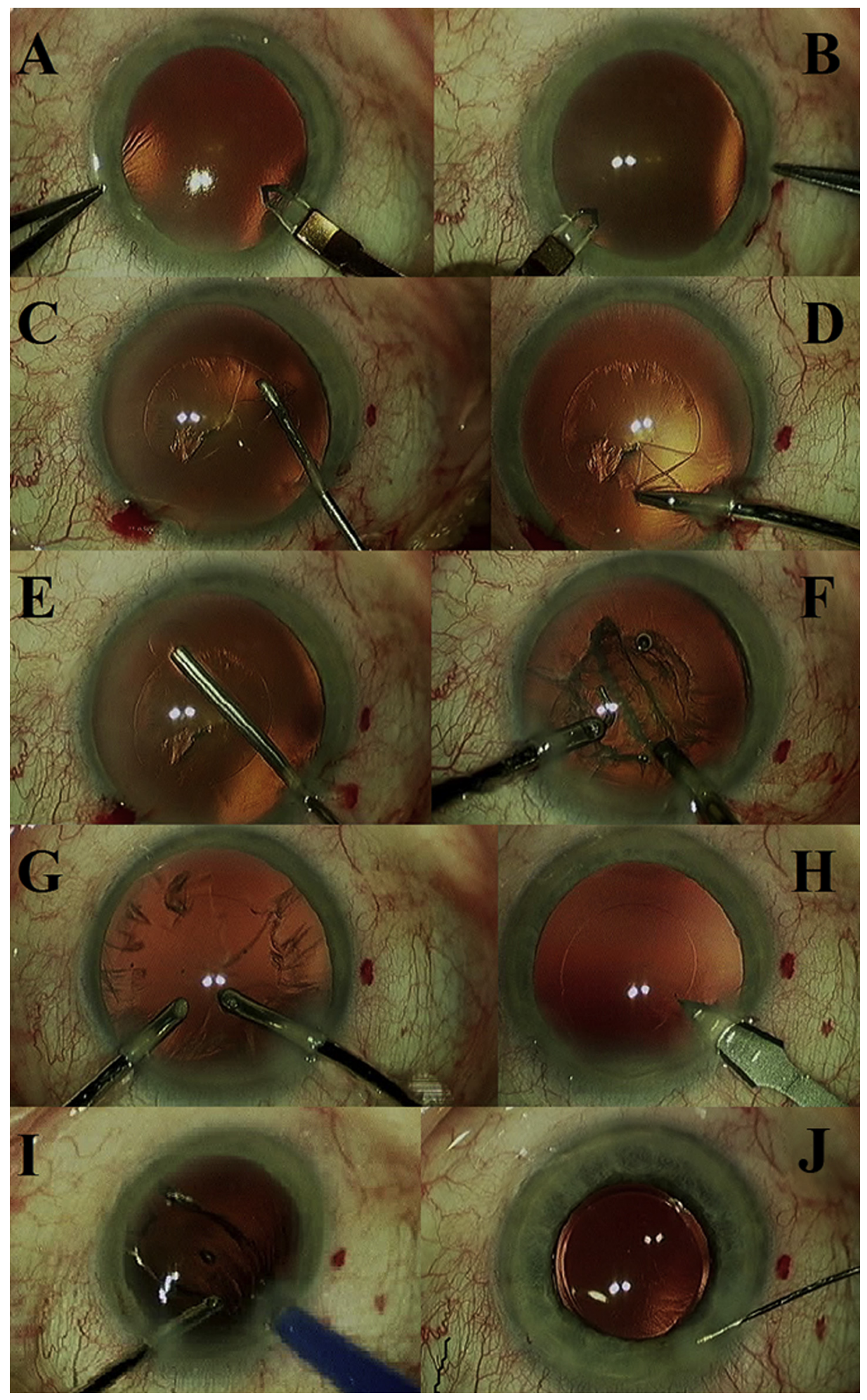

Figure 1. Bimanual MICS surgical technique. $A$ and $B$ : Creation of a $1.4 \mathrm{~mm}$ microincision. $C$ and $D$ : Continuous curvilinear capsulorhexis performed with a cystotome and microforceps. E: Hydrodissection. F: Microphacoemulsification (stop-and-chop technique). G: Bimanual I/A. H: Right microincision enlargement to $1.8 \mathrm{~mm}$. I: Intraocular lens implantation. J: Microincision hydrosuture.

\section{Postoperative Assessment}

Postoperative examinations were performed at 7 days and 30 days by the same experienced physician. Examinations included CDVA, corneal pachymetry, corneal astigmatism, and endothelial microscopy.

\section{Statistical Analysis}

All data were recorded in a database (Excel 2010, Microsoft Corp.) and analyzed for statistical review using the Student $t$ test. A $P$ value less than 0.05 was considered statistically significant. 


\section{RESULTS}

Combined, the 3 surgeons in training (V.V., T.V., M.F.) performed bimanual MICS in 150 eyes (78 right, 72 left) of 131 patients. The mean age of the 49 men and 82 women was 77.4 years \pm 6.7 (SD) (range 55 to 91 years). One of the following IOLs was successfully implanted: Akreos MI60 (Bausch \& Lomb) in 137 eyes, Tecnis ZA9003 (Abbott Medical Optics, Inc.) in 5 eyes, Tecnis ZCB00 in 2 eyes (Abbott Medical Optics, Inc.), Acrysof SN60WF (Alcon Laboratories, Inc.) in 4 eyes, Akreos Adapt-AO (Bausch \& Lomb) in 1 eye, and Micro A (PhysIOL S.A.) in 1 eye. One hundred forty-three IOLs were implanted in the bag, and 7 were implanted in the sulcus because of intraoperative complications.

\section{Intraoperative Parameters}

The mean total surgical time was $27.80 \pm 8.84$ minutes; the mean phacoemulsification time, 1.15 \pm 0.41 minutes; and the mean EPT, $3.64 \pm 1.07$ seconds. The mean final size of the enlarged incision was $1.88 \pm 0.24 \mathrm{~mm}$. The mean volume of balanced salt solution used was $251 \pm 69 \mathrm{~mL}$.

\section{Intraoperative Complications}

Table 2 shows the intraoperative complications, which occurred in 18 cases (12.0\%). Figures 2 to 4 show cases of iris prolapse. Of the cases of capsule rupture without vitreous loss, 2 were of the anterior capsule and were caused by capsulorhexis failure and 2 were of the posterior capsule. Of the cases of posterior capsule rupture with vitreous loss (Figure 5),

\begin{tabular}{|lc|}
\hline \multicolumn{2}{|l|}{ Table 2. Intraoperative and postoperative complications. } \\
\hline Complication & Cases, n (\%) \\
\hline Intraoperative & \\
$\quad$ Iris prolapse & $10(6.6)$ \\
Capsule rupture without vitreous loss & $4(2.7)$ \\
Posterior capsule rupture with vitreous loss & $3(2.0)$ \\
IOL in the sulcus for marked zonular laxity & $1(0.7)$ \\
Postoperative & $1(0.7)$ \\
Displacement of IOL loop from capsular bag & $2(1.3)$ \\
Iris prolapse in a surgical incision & $1(0.7)$ \\
Hypothalamia + corneal suture & $1(0.7)$ \\
Anterior capsule phimosis & \\
\hline IOL $=$ intraocular lens & \\
\hline
\end{tabular}

1 was caused by capsulorhexis failure and 1 was a result of IOL implantation in the sulcus because of marked zonular laxity. In the 8 cases with major complications (capsule rupture with or without vitreous loss and zonular laxity), the supervising surgeon took over and completed the surgery, implanting the IOL in the sulcus; before IOL implantation, anterior vitrectomy was performed in cases with vitreous loss. In 1 case of iris prolapse, the experienced surgeon performed a dry 25-gauge pars plana vitrectomy to decrease posterior positive pressure from the vitreous chamber.

In 10 cases $(6.7 \%)$, the IOL was not implanted through the microincision on the trainee surgeon's first attempt. Proper IOL implantation was achieved during a second attempt (Figure 6).

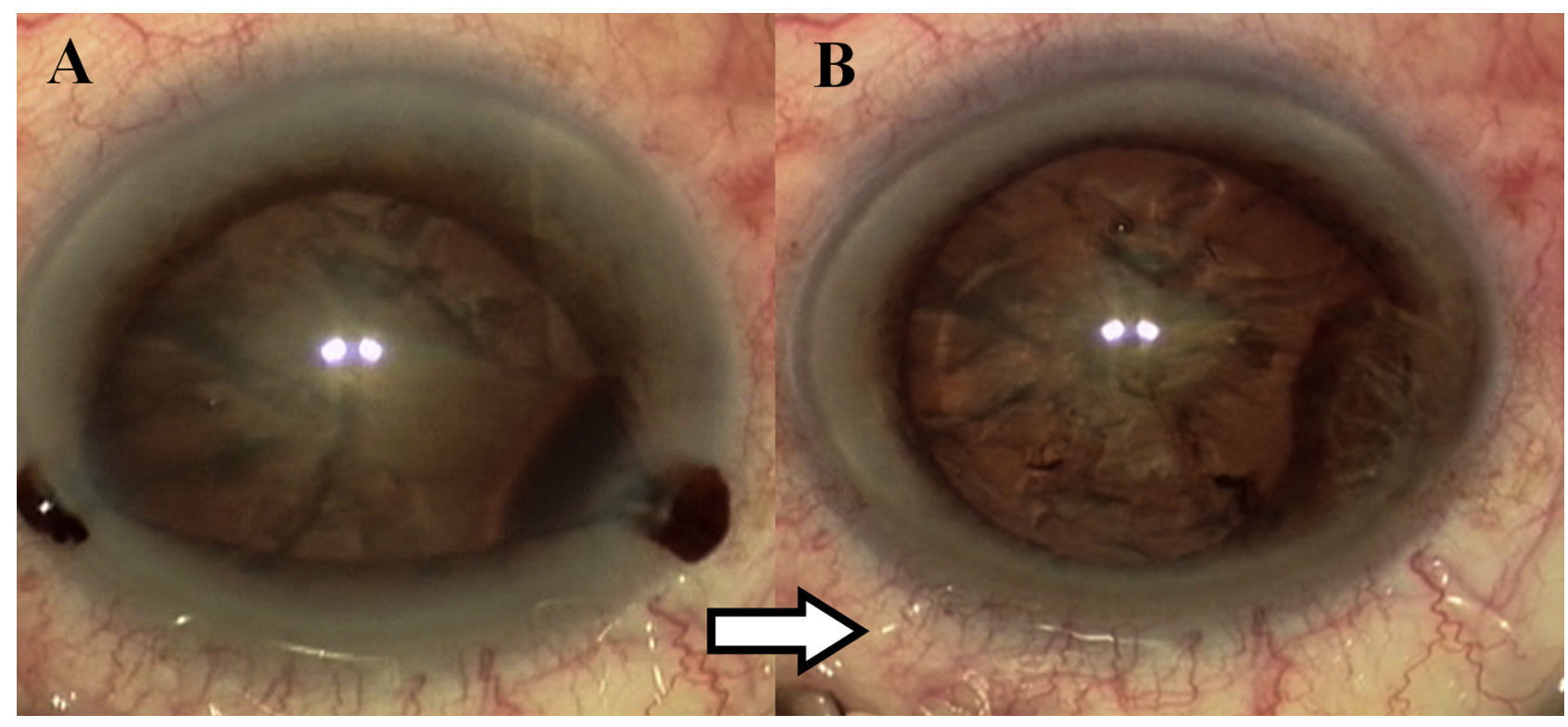

Figure 2. A: Intraoperative iris prolapse through both corneal microincisions. B: Iris trauma after the iris is repositioned. 


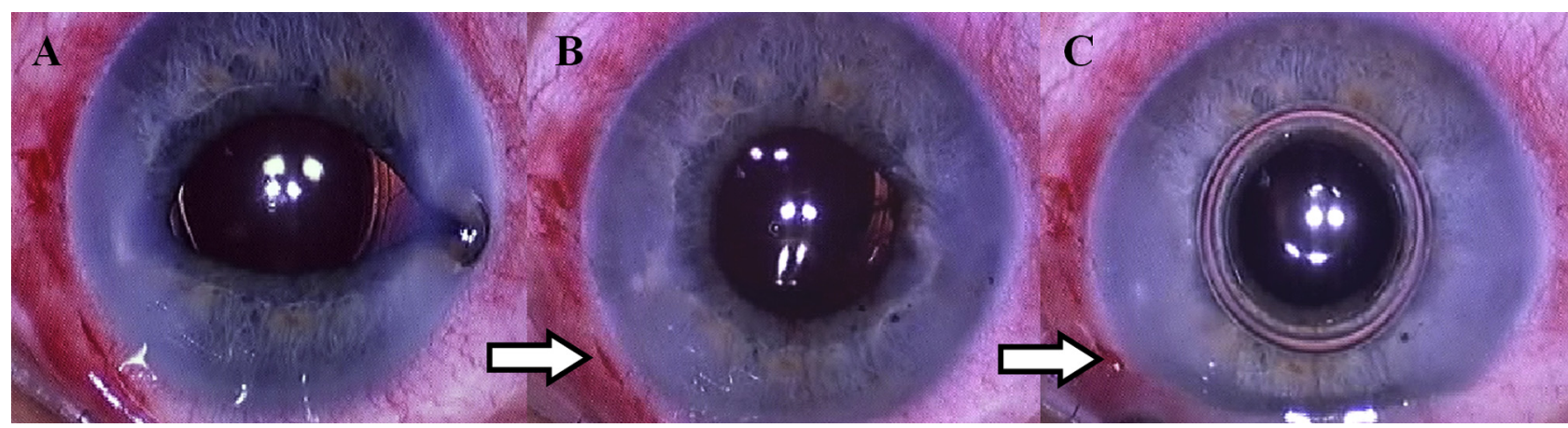

Figure 3. A: Intraoperative iris prolapse through a corneal microincision. $B$ : Iris repositioning. $C$ : Air bubble injection into anterior chamber at the end of surgery.

\section{Postoperative Complications}

Table 2 shows the postoperative complications, which occurred in 5 cases $(3.3 \%)$. The case of loop displacement of the IOL from the capsular bag occurred 7 days after surgery and the case of postoperative anterior chamber narrowing at 5 days. Figure $7, A$, shows a case of capsulorhexis phimosis. All postoperative iris prolapses were in eyes in which iris trauma occurred during surgery. The anterior capsule phimosis occurred 1 month after surgery; it was treated with a neodymium:YAG (Nd:YAG) laser capsulotomy (Figure 7, B). All cases with postoperative complications subsequently had surgery by the supervising surgeon for IOL or iris repositioning with a corneal suture (Figures 8 and 9).

\section{Outcome Measures}

Table 3 shows the CDVA, astigmatism, corneal pachymetry, and endothelial cell density preoperatively as well as 7 days and 30 days postoperatively. The CDVA was statistically significantly better postoperatively than preoperatively $(P<.05)$. Although there was a decrease in astigmatism postoperatively, it was not statistically significant ( 7 days, $P=.55$; 30 days, $P=.29$ ).

The mean increase in corneal pachymetry over the preoperative value was $24.08 \pm 36.05 \mu \mathrm{m}$ at 7 days and $7.42 \pm 22.01 \mu \mathrm{m}$ at 30 days. The increase was statistically significant at 7 days $(P<.05$, Student $t$ test $)$ but not at 30 days $(P=.12$, Student $t$ test).

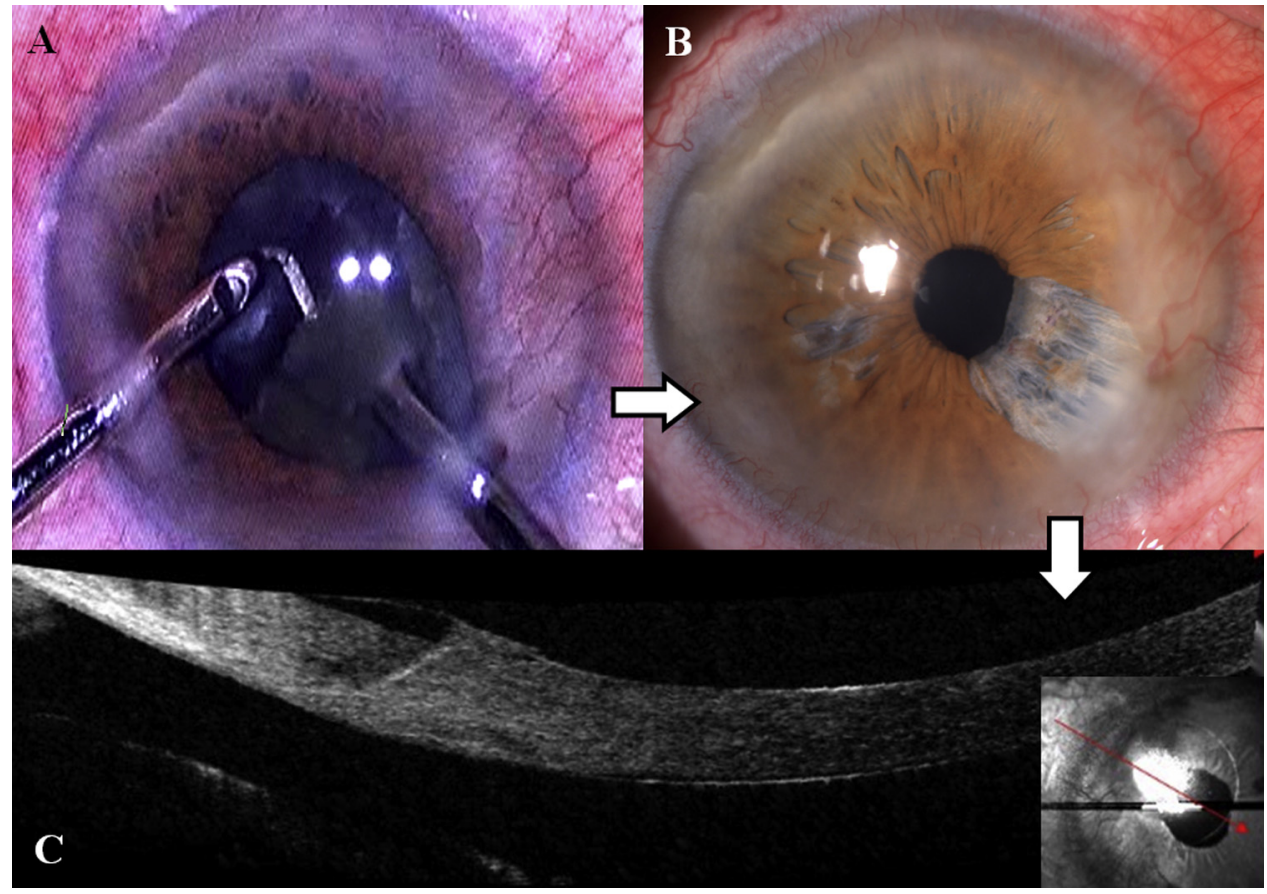

J CATARACT REFRACT SURG - VOL 41, JANUARY 2015
Figure 4. Cataract in intraoperative floppy-iris syndrome and pterygium. A: Intraoperative iris prolapse through the right corneal microincision. B: After 3 weeks, the pupil is round; the lesion in the iris area previously prolapsed is evident in backlight retroillumination. C: The A-S OCT scan showing "posterior wound retraction" at the microincision site (inner side) with small local Descemet detachment. 


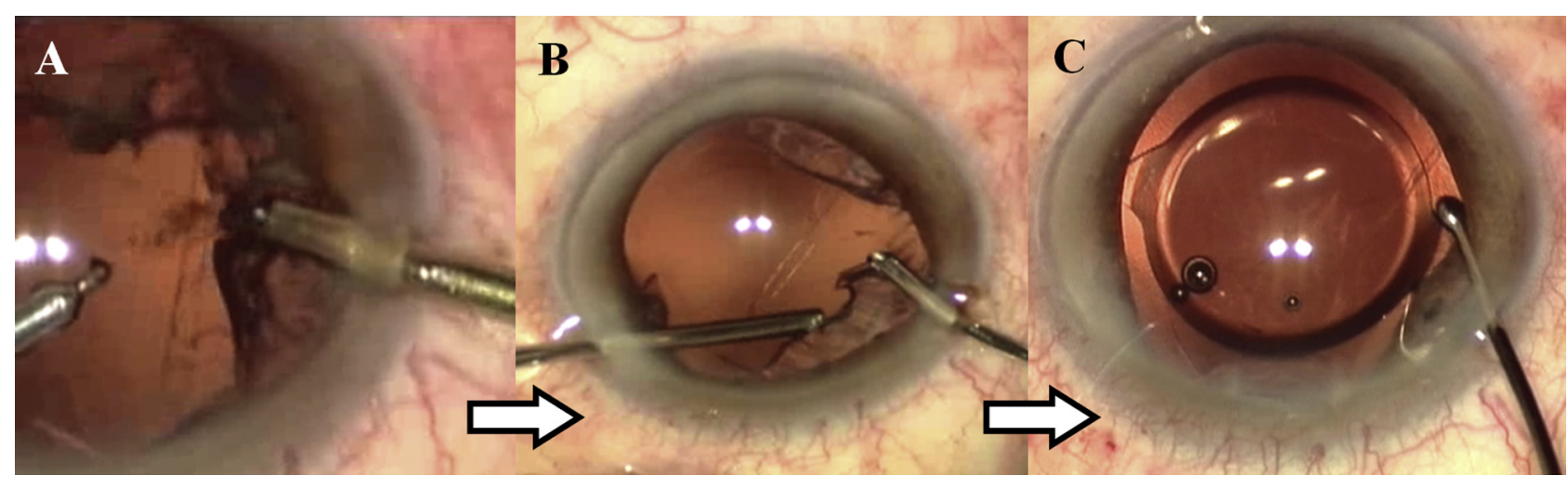

Figure 5. $A$ and $B$ : Posterior capsule rupture with vitreous loss followed by anterior vitrectomy. C: Intraocular lens implantation in the sulcus.

The mean decrease in the ECC over the preoperative value was $474.34 \pm 429.99$ cells $/ \mathrm{mm}^{2}$ at 7 days and $496.50 \pm 469.66$ cells $/ \mathrm{mm}^{2}$ at 30 days. The decrease was statistically significant at both time points $(P<.05)$.

In cases with major complications (capsule rupture, vitreous loss, IOL implantation in the sulcus for zonular laxity), the mean astigmatism was $1.01 \pm 0.48 \mathrm{D}$ preoperatively, $1.32 \pm 1.05 \mathrm{D} 7$ days postoperatively, and $1.26 \pm 0.87 \mathrm{D}$ at 30 days. However, the mean CDVA improved from $0.32 \pm 0.24$ preoperatively to $0.66 \pm 0.23$ at 7 days and $0.79 \pm 0.21$ at 30 days.

\section{DISCUSSION}

In this study, we evaluated the first experience with bimanual MICS of 3 surgeons in training. The outcome measures included intraoperative surgical parameters, intraoperative and postoperative complications, and visual outcomes 7 days and 30 days after surgery.

The literature on bimanual MICS performed by experienced surgeons reports a mean total surgical time ranging from $10.62 \pm 2.37$ minutes to $18.79 \pm$ 6.58 minutes and a mean phacoemulsification time ranging from $0.07 \pm 0.03$ minutes to $0.19 \pm$ 0.23 minutes. ${ }^{6,7}$ The values in our study were higher $(27.80 \pm 8.84$ minutes and $1.15 \pm 0.41$ minutes, respectively). We believe the higher values are the result of the lack of experience, and thus slower movements, of the surgeons in training. Also, these surgeons used low levels of ultrasound for a longer time. The EPT in our study was $3.64 \pm 1.07$ seconds; values for experienced surgeons are reported to range from $1.29 \pm 1.85$ seconds to $3.86 \pm 2.91$ seconds. ${ }^{6,7}$ Reported rates for the mean volume of balanced salt solution used range from $114.51 \pm 32.23 \mathrm{~mL}$ to $119.54 \pm 50.58 \mathrm{~mL}{ }^{6-8}$ which are less than half the mean volume in our study ( $251 \pm$ $69 \mathrm{~mL}$ ); this may be related to the continuous infusion preferred by the surgeons in training.

Intraoperative complications occurred in 18 cases $(12.0 \%)$ in our study; the most frequent complication was iris prolapse. In a study of resident-performed conventional phacoemulsification by Lee et al., ${ }^{9}$ iris trauma occurred in 8 (3.54\%) of 226 cases; Rutar et al. ${ }^{10}$ report a similar incidence (8 [2.5\%] of 320 cases). Because microincisions confer better anterior chamber stability, the bimanual MICS technique reduces the risk for iris prolapse. Thus, this technique is recommended in cases of

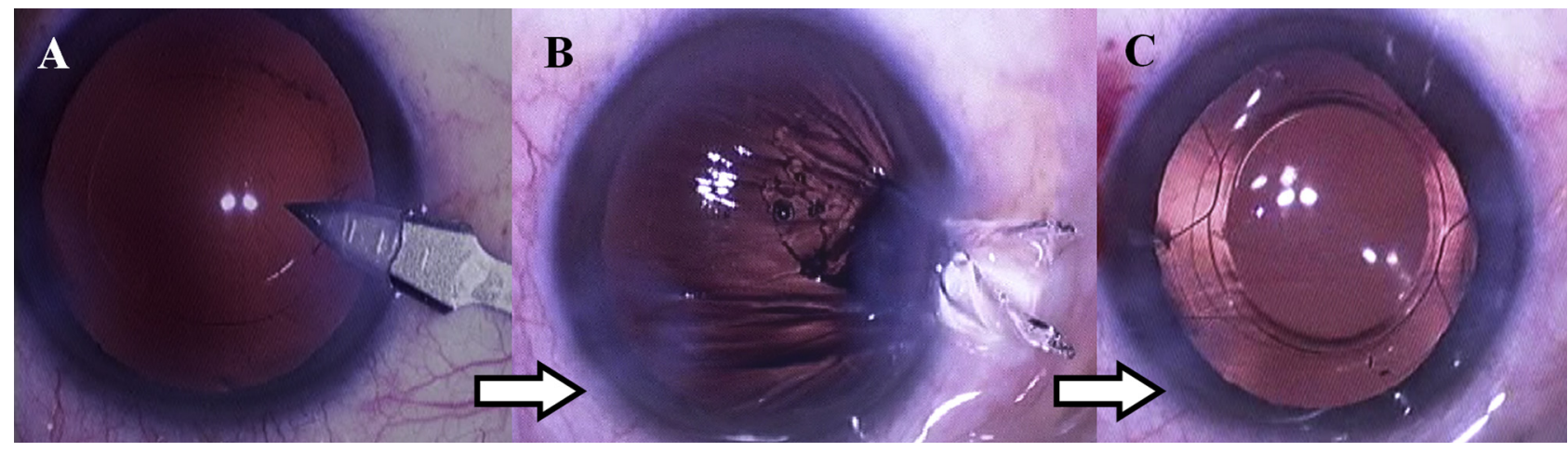

Figure 6. A: Enlargement of the right microincision to $1.7 \mathrm{~mm}$. B: Failed IOL insertion through the microincision. C: Proper IOL implantation at the second attempt. 


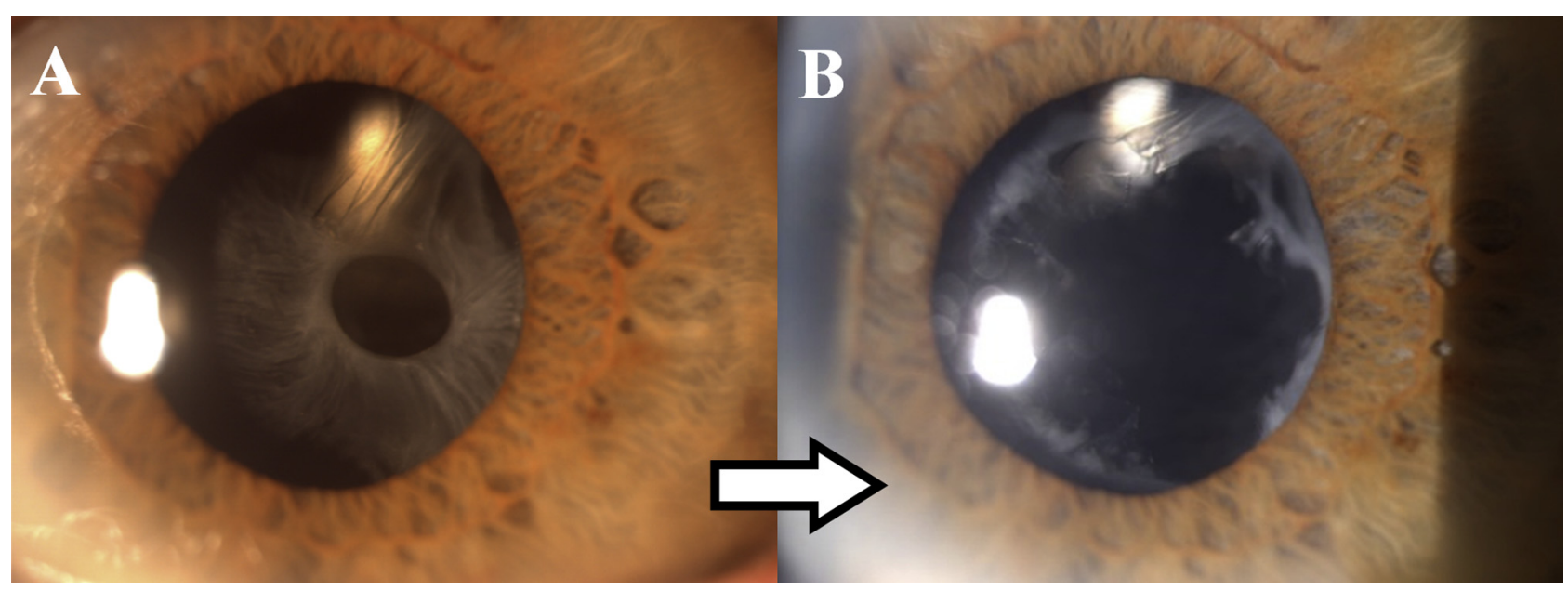

Figure 7. A: Capsulorhexis phimosis 1 month after surgery. B: Resolution after Nd:YAG laser treatment to enlarge the capsulorhexis.

severe intraoperative floppy-iris syndrome (IFIS). ${ }^{11,12}$ In our study, the rate of iris prolapse was fairly high $(6.6 \%)$, which could be explained by 2 factors. The first and main factor is poor construction of the microincision, which will negatively affect subsequent surgical steps. In coaxial MICS, the main incision is between $1.8 \mathrm{~mm}$ and $2.2 \mathrm{~mm}$ and it is made with a 2-plane or 3-plane (tunnel shape) corneal architecture. In the bimanual MICS technique, the incisions are $1.4 \mathrm{~mm}$ and are created with a diamond knife on a single plane. Thus, the main incision must be enlarged for IOL implantation. Without a 2-plane or 3-plane architecture, it is important to attain correct inclination of the microincision. Second, iris prolapse can occur if the surgeon has difficulty handling instruments with the nondominant hand. The irrigating chopper in bimanual MICS is bigger than that used in coaxial MICS, and this requires the surgeon to have confidence using the nondominant hand. Figure 10 shows a correctly constructed microincision and an incorrectly constructed microincision. All cases of iris prolapse in our study occurred during the first 20 cases performed by each surgeon, frequently in cases of IFIS-associated cataract (almost 70\% of cases). Figure 4 shows a case of IFIS in which the microincision was too short, leading to intraoperative iris prolapse. A corneal suture was placed in the microincision at the end of surgery. Three weeks after surgery, when the suture was removed, posterior wound retraction ${ }^{13}$ with small local Descemet detachment at the microincision site was noticed on anterior segment optical coherence tomography (AS-OCT).

Anterior capsule rupture can be caused by an incomplete CCC or one that is not curvilinear. In our study, it occurred in 2 cases $(1.3 \%), 1$ of which was further complicated by posterior capsule rupture and vitreous loss. In the study of phacoemulsification performed by residents by Lee et al., ${ }^{9}$ capsulorhexis failure occurred in $21(9.29 \%)$ of 226 cases. In our study, the surgeons in training created the capsulorhexis with a surgeon-bent cystotome and a microforceps. A large capsule flap was made, after which the capsulorhexis was completed using radial and circumferential traction movements. Microincisions help prevent corneal tunnel deformation and corneal striae. ${ }^{14}$ Moreover, the small instruments permit good visibility of the surgical field. Finally, if the supervising surgeon must take over the surgery, the structure of the bimanual microincision offers him or her a greater possibility of completing the capsulorhexis with the right hand or the left hand. In our case study, the capsulorhexis was completed by the supervising surgeon in 2 cases.

There are several reports of posterior capsule rupture with vitreous loss in resident-performed phacoemulsification. Bhagat et al. ${ }^{15}$ report posterior capsule rupture in $6.7 \%$ of cases and vitreous loss in $5.4 \%$. Rutar et al. ${ }^{10}$ report a $4.7 \%$ incidence of major complications, the main one $(3.1 \%)$ being vitreous loss. Carricondo et al. $^{16}$ found a mean incidence of posterior capsule rupture of $8.05 \%$ and vitreous loss of $6.13 \%$. In a recent study by Woodfield et al., ${ }^{17}$ capsule rupture occurred in between $4.8 \%$ and $7.0 \%$ of cases with the incidence of vitreous loss ranging from $3.0 \%$ to $4.8 \%$. In a recent study by Briszi et al., ${ }^{18}$ most surgeries and complicated cases were performed using general anesthesia; posterior capsule tear occurred in $3.8 \%$ of surgeries and vitreous loss, in $2.8 \%$. In our study, there were 4 cases (2.7\%) of capsule rupture without vitreous loss and 3 with vitreous loss $(2.0 \%)$, which is in line with previously reported data. In the case of posterior capsule rupture, bimanual MICS has the advantage of maintaining a stable anterior chamber as a result of the presence of constant pressure. This technique, in which infusion is 


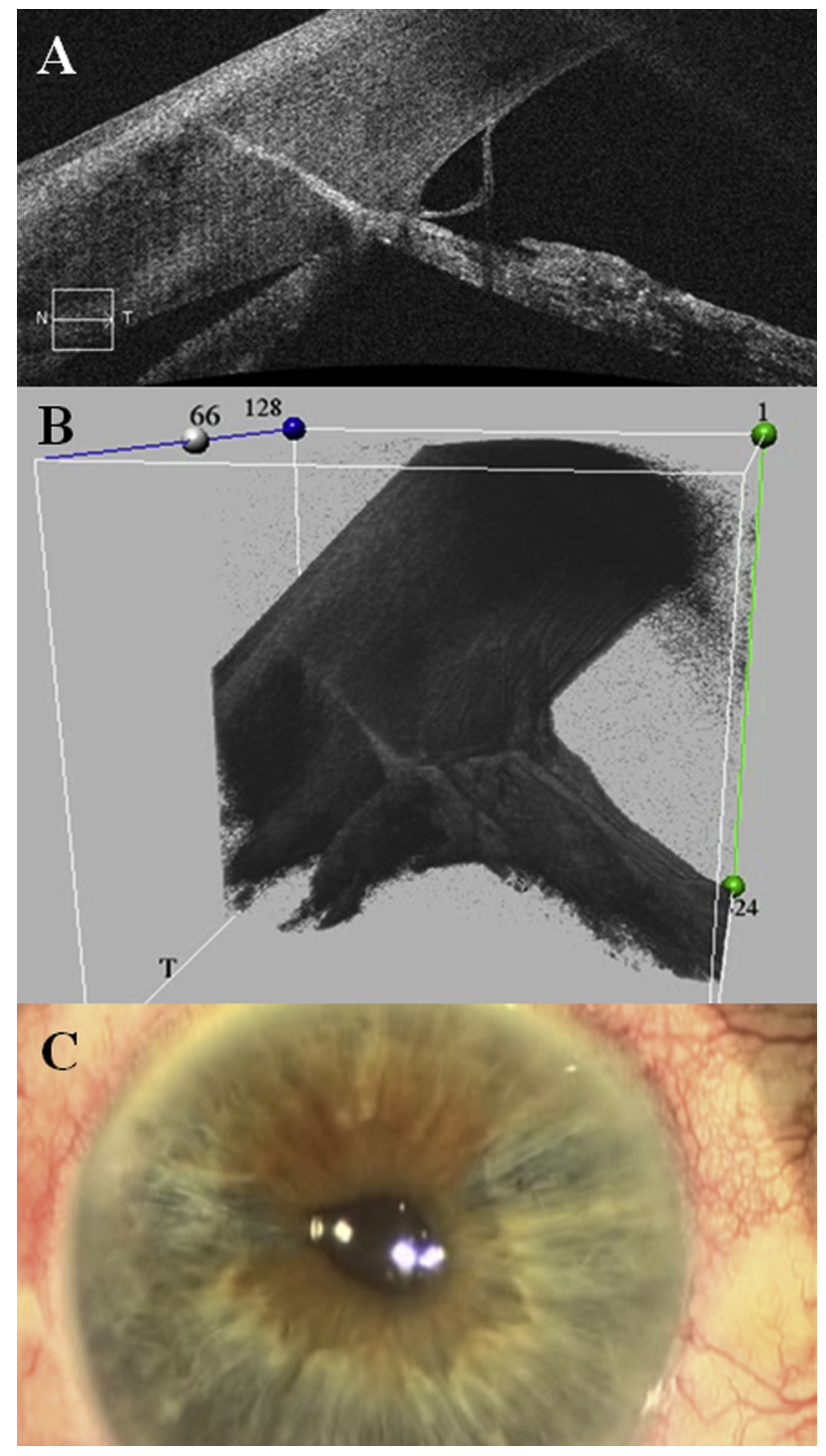

Figure 8. $A$ to $C$ : Postoperative iris prolapse through the corneal microincision $(\mathrm{N}=$ nasal; $\mathrm{T}=$ temporal $)$. separated from the phaco tip, permits the surgeon to direct the flow toward the desired direction independent from the dominant-hand maneuvers, allowing better control of the posterior capsule (keeping the posterior capsule down and far from the phaco tip) and the lens fragments. This is especially helpful to less experienced surgeons.

Moreover, the first attempt at IOL insertion by the surgeon in training failed in 10 cases; this was due to inexperience with the injection procedure and in some cases, the incision was smaller than the $1.8 \mathrm{~mm}$ necessary for IOL implantation. The surgeon must insert the IOL without hesitation and with the help of a forceps. It is important that the injector remain still and resting on the corneal wound so the IOL can be injected without hesitation on the part of the surgeon.

In all 5 patients with major intraoperative complications (capsule rupture with vitreous loss, IOL in the sulcus for zonular laxity), we performed AS-OCT at 7 days and 30 days to determine whether there was intraretinal fluid in the macula. We did not find any case of cystoid macular edema within 1 month of surgery.

Postoperative iris prolapse occurred in 2 eyes in our study. In both cases, secondary surgery was performed by the experienced surgeons to reposition the prolapsed iris tissue. A case of postoperative IOL displacement was managed using surgical IOL loop repositioning in the capsular bag. One case of anterior chamber narrowing occurred 5 days after surgery; a corneal suture was positioned at the main microincision site, restoring the anterior chamber depth.

A case of capsulorhexis phimosis occurred at 1 month. Previously, we described a case of complete capsulorhexis phimosis after implantation of the IOL (Akreos MI60) used in the present case. ${ }^{19}$ In the earlier case, the phimosis occurred after 6 months and surgery was performed to reduce it. In the present case, we used an Nd:YAG laser to open and enlarge the capsulorhexis; the final CDVA was 1.0.

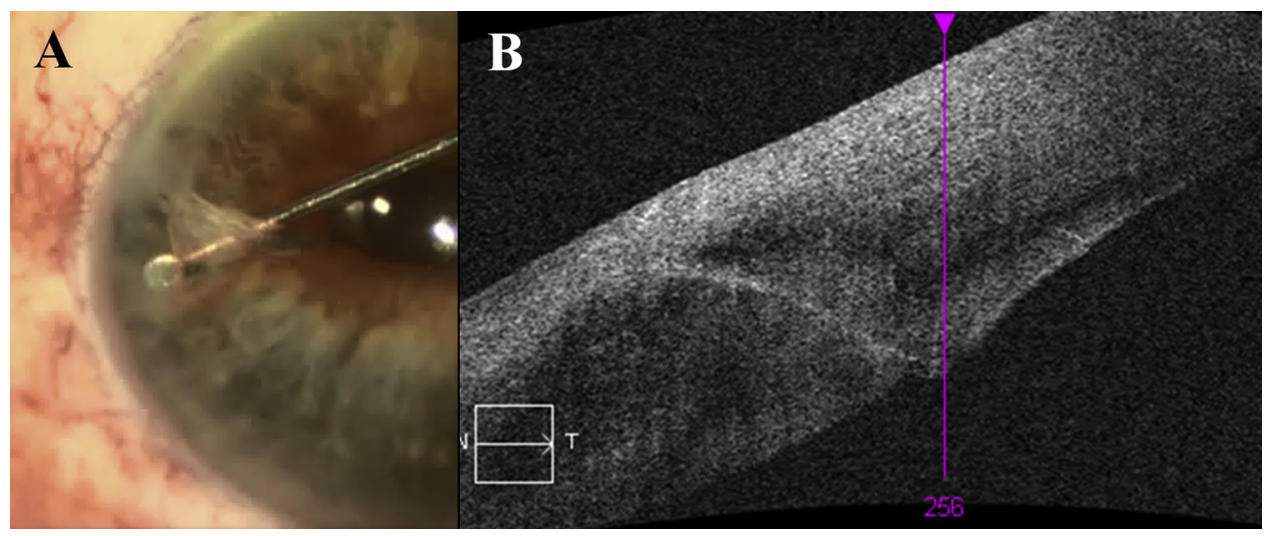

Figure 9. $A$ : Iris repositioning (same case as in Figure 8). B: An AS-OCT scan showing the microincision after iris repositioning $(\mathrm{N}=$ nasal; $\mathrm{T}=$ temporal). 
Table 3. Preoperative and postoperative parameters.

\begin{tabular}{lccc}
\hline & & Mean \pm SD & \\
\cline { 2 - 4 } Parameter & Preop & 7 Days Postop & 30 Days Postop \\
\hline CDVA & $0.40 \pm 0.18$ & $0.87 \pm 0.21$ & $0.92 \pm 0.19$ \\
Astigmatism $(\mathrm{D})$ & $0.97 \pm 0.62$ & $0.92 \pm 0.65$ & $0.88 \pm 0.63$ \\
Corneal pachymetry $(\mu \mathrm{m})$ & $556.87 \pm 35.75$ & $581.93 \pm 45.72$ & $563.48 \pm 38.50$ \\
ECD $\left(\right.$ cells $\left./ \mathrm{mm}^{2}\right)$ & $2416.96 \pm 423.10$ & $1945.32 \pm 516.42$ & $1915.27 \pm 538,02$ \\
\hline CDVA $=$ corrected distance visual acuity (expressed in decimals on a $10 / 10=1$ scale basis $[$ eg, $1 / 10=0.1,2 / 10=0.2]) ;$ ECD $=$ endothelial cell density
\end{tabular}

We found a significant improvement in CDVA, as has been reported for cases performed by experienced surgeons. ${ }^{6-8}$ Moreover, the SIA was not significant, which agrees with findings in other studies of bimanual MICS. ${ }^{4,20}$

In the cases with major complications (capsule rupture, vitreous loss, implantation in the sulcus due to zonular laxity), there was an increase in mean astigmatism $(0.32 \pm 1.06 \mathrm{D}$ at 7 days and $0.25 \pm 1.04 \mathrm{D}$ at 30 days). The reason might be because the surgeon had to enlarge the incision to $2.2 \mathrm{~mm}$ or $2.8 \mathrm{~mm}$ for IOL implantation in the sulcus. However, in these cases, there was improvement in the mean CDVA $(0.34 \pm 0.23$ at 7 days and $0.47 \pm 0.20$ at 30 days).

As expected, the change in corneal pachymetry from preoperatively to postoperatively was not significant. In some cases, there was corneal edema in the main incision the day after surgery; the edema resolved within 1 week.

Finally, the endothelial cell loss (mean 19.7\% at 30 days; range $0 \%$ to $44 \%$ ) was statistically significant and similar to results in a study by O'Brien et al. ${ }^{21}$ of conventional phacoemulsification cataract surgery performed by residents (mean loss $11.6 \%$; range $0 \%$ to $57 \%$ ). However, it is much higher than values given for bimanual MICS performed by experienced surgeons (range 6.2\% to 9.27\%). ${ }^{7,22,23}$ However, in our study, the endothelial cell loss did not affect the final CDVA or corneal transparency.

In conclusion, the aim of our study was to evaluate the results and complication rates of bimanual MICS performed by surgeons in training. To our knowledge, ours is the first study of this topic. The high incidence of iris prolapse might be related to the wrong inclination and position of the microincisions and the use of the nondominant hand, which many surgeons find to be one of the most difficult steps in learning bimanual MICS. Capsule rupture and vitreous loss did not occur with more frequency than reported in studies of the coaxial technique and should be addressed in terms of the learning curve of cataract surgery in general rather than the specific surgical

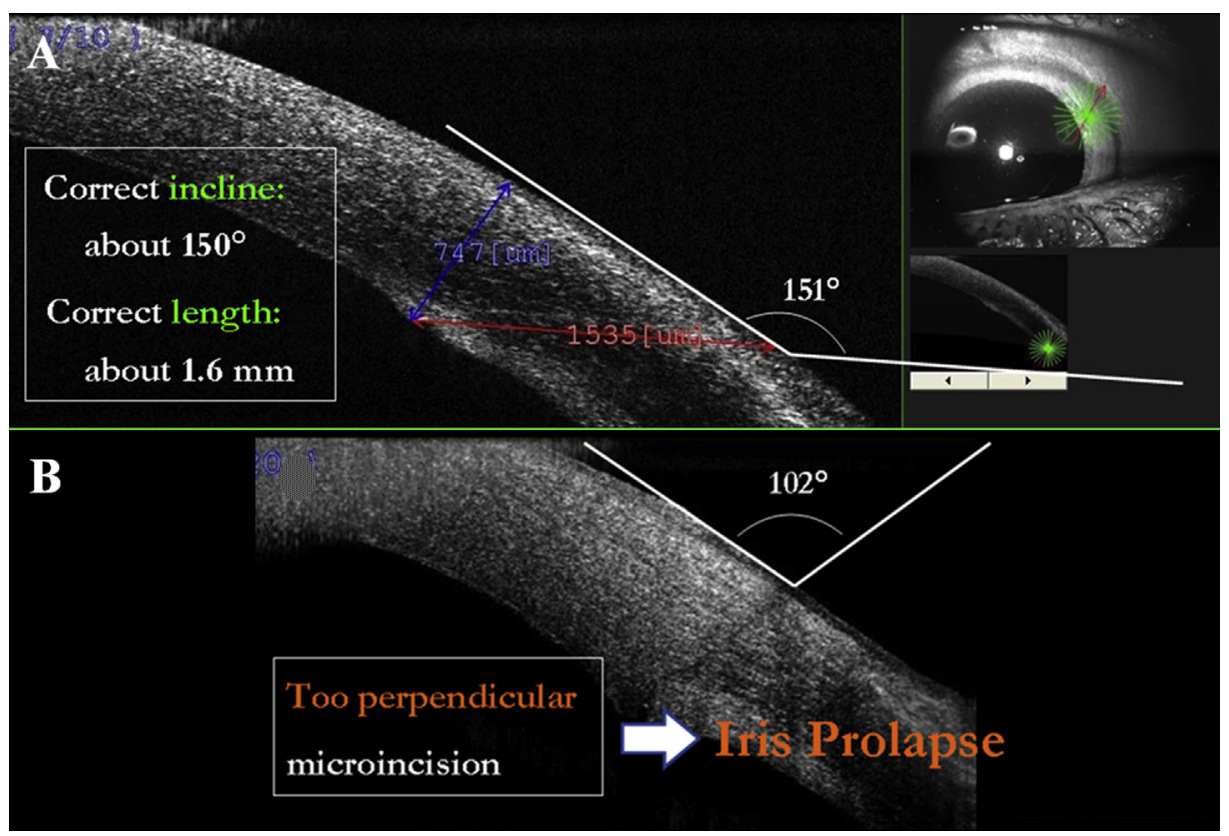

Figure 10. A: Correct microincision. $B$ : Incorrect microincision. 


\begin{tabular}{|l|l|l|}
\hline Step & TO DO/ Advantages & NOT TO DO/ Disadvantages \\
\hline $\begin{array}{l}\text { CCI } \\
\text { (microincisions) }\end{array}$ & $\begin{array}{l}\text { Correct angle: } 150^{\circ} \\
\text { Correct length: } 1.6 \mathrm{~mm} \\
\text { Correct distance between } \\
\text { microincisions: } 120^{\circ}\end{array}$ & $\begin{array}{l}\text { Not too perpendicular/short (iris } \\
\text { prolapse risk) }\end{array}$ \\
\hline Capsulorhexis & $\begin{array}{l}\text { Possibility of performing } \\
\text { capsulorhexis with both hands; } \\
\text { better visibility with smaller } \\
\text { instruments }\end{array}$ & $\begin{array}{l}\text { If microincision is too long: difficult to } \\
\text { perform capsulorhexis due to corneal } \\
\text { folds }\end{array}$ \\
\hline Phaco & $\begin{array}{l}\text { Better visibility with smaller } \\
\text { instruments; lateral inclination } \\
\text { of the chopper so irrigation keeps } \\
\text { posterior capsule down }\end{array}$ & $\begin{array}{l}\text { Pay attention to the left hand, never } \\
\text { retract the irrigation; pay attention to } \\
\text { the chopper to avoid posterior capsule } \\
\text { rupture }\end{array}$ \\
\hline I/A & $\begin{array}{l}\text { Possibility of changing hands } \\
\text { Insert IOL with decision and } \\
\text { with the help of a forceps; } \\
\text { remain still and resting on the } \\
\text { corneal wound to inject without } \\
\text { hesitation }\end{array}$ & \\
\hline
\end{tabular}

Figure 11. Tips for learning bimanual MICS. technique. In our experience, an important advantage of the bimanual MICS technique is that an experienced surgeon can take over the surgery when a complication occurs. For example, in the case of CCC failure, the experienced surgeon can take over and complete it from the temporal or nasal side. When vitreous loss occurs, the anterior chamber stability provides an element of safety when managing the complication. We summarize the main advantages and disadvantages of this technique in Figure 11. We found the bimanual MICS technique was a safe and effective technique even when performed by surgeons in training and may be no more difficult to learn than the traditional coaxial technique.

\section{WHAT WAS KNOWN}

- The bimanual MICS technique for cataract surgery enables incisions of $1.5 \mathrm{~mm}$ or smaller and is this less invasive than conventional traditional coaxial phacoemulsification.

- The technique provides increased anterior chamber stability, the possibility of directing the instruments as required and using the right hand or left hand, and better visibility of the surgical field because of the small.

\section{WHAT THIS PAPER ADDS}

- Bimanual MICS performed by surgeons in training had an acceptably low complication rate comparable to that in previous studies of conventional coaxial phacoemulsification.

- Some features of the bimanual MICS technique are helpful to less experienced surgeons and allow easier management of complications by a supervising surgeon.

\section{REFERENCES}

1. Alio JL. What does MICS require? The transition to microincisional surgery. In: Alio JL, Rodriguez Prats JL, Galal A, eds, MICS: Micro-Incision Cataract Surgery. El Dorado, Republic of Panama, Highlights of Ophthalmology International; $1-4$

2. Cavallini GM, Masini C. Microfacoemulsificazione bimanuale: origine e definizioni. In: Cavallini GM, ed, Microfacoemulsificazione Bimanuale Nella Chirurgia Della Cataratta. Modena, Italy, Athena Audiovisuals, 2006; 15-19

3. Vasavada V, Vasavada V, Raj SM, Vasavada AR. Intraoperative performance and postoperative outcomes of microcoaxial phacoemulsification; observational study. J Cataract Refract Surg 2007; 33:1019-1024

4. Cavallini GM, Lugli N, Campi L, Lazzerini A, Longanesi L. Surgically induced astigmatism after manual extracapsular cataract extraction or after phacoemulsification procedure. Eur J Ophthalmol 1996; 6:257-263

5. Chylack LT Jr, Wolfe JK, Singer DM, Leske MC, Bullimore MA, Bailey IL, Friend J, McCarthy D, Wu S-Y; for the Longitudinal Study of Cataract Study Group. The Lens Opacities Classification System III. Arch Ophthalmol 1993; 111:831-836. Available at: http://www.chylackinc.com/LOCS_III/LOCS_III_Certifica tion_files/LOCS_III_Reprint_pdf.pdf. Accessed August 23, 2014

6. Cavallini GM, Campi L, Masini C, Pelloni S, Pupino A. Bimanual microphacoemulsification versus coaxial miniphacoemulsification: prospective study. J Cataract Refract Surg 2007; 33:387-392

7. Can I, Takmaz T, Yıldız Y, Bayhan HA, Soyugelen G, Bostancı B. Coaxial, microcoaxial, and biaxial microincision cataract surgery; prospective comparative study. J Cataract Refract Surg 2010; 36:740-746

8. Kahraman G, Amon M, Franz C, Prinz A, Abela-Formanek C. Intraindividual comparison of surgical trauma after bimanual microincision and conventional small-incision coaxial phacoemulsification. J Cataract Refract Surg 2007; 33:618-622

9. Lee J-S, Hou C-H, Yang M-L, Kuo JZ-C, Lin K-K. A different approach to assess resident phacoemulsification learning curve: analysis of both completion and complication rates. Eye 2009; 23:683-687. Available at: http://www.nature.com/eye/ journal/v23/n3/pdf/6703103a.pdf. Accessed August 23, 2014 
10. Rutar T, Porco TC, Naseri A. Risk factors for intraoperative complication in resident-performed phacoemulsification surgery. Ophthalmology 2009; 116:431-436

11. Chang DF, Braga-Mele R, Mamalis N, Masket S, Miller KM, Nichamin LD, Packard RB, Packer M; for the ASCRS Cataract Clinical Committee. ASCRS white paper: clinical review of intraoperative floppy-iris syndrome. J Cataract Refract Surg 2008; 34:2153-2162

12. Hu YJ, Hou P. Managing iris prolapse [letter]. J Cataract Refract Surg 2010; 36:1064; reply by NL Tint, AM Yeung, P Alexander, 1064-1065

13. Cavallini GM, Campi L, Torlai G, Forlini M, Fornasari E. Clear corneal incisions in bimanual microincision cataract surgery: long-term wound-healing architecture. J Cataract Refract Surg 2012; 38:1743-1748

14. O'Connor JC, O'Connell ED, Sciscio A, Mulhern MG. The laparotomy incision: a technique to facilitate capsulorhexis in microincision cataract surgery. Ophthalmic Surg Lasers Imaging 2008; 39:519-521

15. Bhagat N, Nissirios N, Potdevin L, Chung J, Lama P, Zarbin MA, Fechtner R, Guo S, Chu D, Langer P. Complications in residentperformed phacoemulsification cataract surgery at New Jersey Medical School. Br J Ophthalmol 2007; 91:1315-1317. Available at: http://www.ncbi.nlm.nih.gov/pmc/articles/PMC 2001026/pdf/1315.pdf. Accessed August 23, 2014

16. Carricondo PC, Morais Fortes ACF, de Carvalho Mourão P, Hajnal M, Kara Jose N. Senior resident phacoemulsification learning curve (corrected from cure). Arq Bras Oftalmol 2010; 73:66-69. Available at: http://www.scielo.br/pdf/abo/v73n1/ v73n1a12.pdf. Accessed August 23, 2014

17. Woodfield AS, Gower EW, Cassard SD, Ramanthan S. Intraoperative phacoemulsification complication rates of secondand third-year ophthalmology residents; a 5-year comparison. Ophthalmology 2011; 118:954-958
18. Briszi A, Prahs P, Hillenkamp J, Helbig H, Herrmann W. Complication rate and risk factors for intraoperative complications in resident-performed phacoemulsification surgery. Graefes Arch Clin Exp Ophthalmol 2012; 250:1315-1320

19. Cavallini GM, Masini C, Campi L, Pelloni S. Capsulorhexis phimosis after bimanual microphacoemulsification and in-the-bag implantation of the Akreos MI60 intraocular lens. J Cataract Refract Surg 2008; 34:1598-1600

20. Wilczyńska O, Wilczyński M, Omulecki W. [Surgically induced astigmatism after bimanual phacoemulsification through microincision and after standard phacoemulsification]. [Polish] Klin Oczna 2010; 112:115-119

21. O'Brien PD, Fitzpatrick P, Kilmartin DJ, Beatty S. Risk factors for endothelial cell loss after phacoemulsificaton surgery by a junior resident. J Cataract Refract Surg 2004; 30:839-843

22. Wilczynski M, Supady E, Piotr Loba, Synder A, PalengaPydyn D, Omulecki W. Comparison of early corneal endothelial cell loss after coaxial phacoemulsification through $1.8 \mathrm{~mm}$ microincision and bimanual phacoemulsification through 1.7 mm microincision. J Cataract Refract Surg 2008; 35:1570-1574

23. Gonen T, Sever O, Horozoglu F, Yasar M, Keskinbora KH. Endothelial cell loss: biaxial small-incision torsional phacoemulsification versus biaxial small-incision longitudinal phacoemulsification. J Cataract Refract Surg 2012; 38:1918-1924

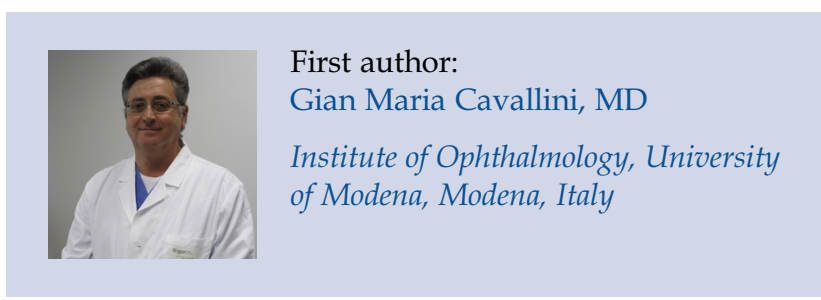

